\title{
Influence of Co-Solvent on the Extraction Behaviour of Uranium and Thorium Nitrates with Organophosphorous Compounds
}

\author{
K. C. Pitchaiah, K. Sujatha, C. V. S. Brahmmananda Rao, N. Sivaraman*, T. G. Srinivasan, \\ K. Nagarajan, P. R. Vasudeva Rao \\ Chemistry Group, Indira Gandhi Centre for Atomic Research, Kalpakkam, India \\ Email: "sivaram@igcar.gov.in
}

Received 13 April 2014; revised 12 May 2014; accepted 8 June 2014

Copyright (C) 2014 by authors and Scientific Research Publishing Inc.

This work is licensed under the Creative Commons Attribution International License (CC BY).

http://creativecommons.org/licenses/by/4.0/

(c) () Open Access

\begin{abstract}
Supercritical Fluid Extraction (SFE) is emerging as a powerful technique in the extraction of metal ions. In the present study, the extraction of nitrates of uranium and thorium in their solid form was carried out using supercritical carbon dioxide $\left(\mathrm{Sc}^{-} \mathrm{CO}_{2}\right)$ modified with various organophosphorous compounds such as dialkylalkyl phosphonates, trialkyl phosphates and trialkyl phosphine oxides in the presence of co-solvents such as methanol, dichlormethane and n-hexane. The influence of ligand and co-solvent on the extraction of the metal nitrates was studied in detail. These studies have established that co-solvent plays an important role in the extraction as well as fractionation of uranium and thorium nitrates. Polar co-solvent, methanol provided faster extraction without fractionation whereas the non-polar solvent, e.g. n-hexane provided some fractionation of metal nitrates though the extraction kinetics was slower.
\end{abstract}

\section{Keywords}

Co-Solvent, Uranium and Thorium, Organophosphorous Compounds

\section{Introduction}

For the past one decade, there has been growing interest in the use of Supercritical Fluid Extraction (SFE) technique for the recovery of metal ions from various matrices and this technique is explored as an alternative to the well established conventional extraction methods. Supercritical fluids have physical properties between those of liquids and gases [1]. The combination of liquid-like densities and gas like properties of supercritical fluids re-

\footnotetext{
*Corresponding author.
}

How to cite this paper: Pitchaiah, K.C., et al. (2014) Influence of Co-Solvent on the Extraction Behaviour of Uranium and Thorium Nitrates with Organophosphorous Compounds. International Journal of Analytical Mass Spectrometry and Chromatography, 2, 33-42. http://dx.doi.org/10.4236/ijamsc.2014.22004 
sults in interesting analytical separations and provides a medium for various organic reactions. $\mathrm{CO}_{2}$ is the most widely used supercritical fluid due to its moderate critical temperature and critical pressure; moreover, it is non-flammable, non-toxic, inexpensive and environmental friendly [1]. The most distinctive properties of the supercritical fluids are their enhanced mass transfer and variable density. The density of supercritical fluid can be fine tuned by varying the pressure and temperature [1]; hence solvating power of carbon dioxide can be easily altered. Supercritical fluids offer faster, efficient and cleaner extraction as $\mathrm{CO}_{2}$ escapes as gas after extraction leaving the solute in its pure form. SFE is attractive technique to the nuclear industry, where the replacement of organic solvents with $\mathrm{Sc}-\mathrm{CO}_{2}$ has the potential to minimize the generation of secondary liquid waste.

Supercritical carbon dioxide is an excellent candidate for the extraction of non-polar and moderately polar compounds. The extraction of polar compounds is generally carried out with $\mathrm{Sc}-\mathrm{CO}_{2}$ containing small quantities of organic solvent e.g. methanol as the co-solvent. The extraction of metal ions is accomplished by the addition of suitable ligand into Sc- $\mathrm{CO}_{2}$ medium [2]-[4]. Addition of organic ligands results in the conversion of charged metal species into neutral metal complexes, which become quite soluble in $\mathrm{Sc}-\mathrm{CO}_{2}$. Supercritical carbon dioxide $\left(\mathrm{Sc}-\mathrm{CO}_{2}\right.$ ) containing chelating agents was employed for the extraction of metal ions such as transition metal ions, lanthanides and actinides [5]-[17]. Sc- $\mathrm{CO}_{2}$ containing ligands such as diketones, fluorinated diketones and trin-butyl phosphate (TBP) was used for the recovery of actinides such as thorium, uranium, plutonium and americium. SFE technique was developed and demonstrated in our laboratory for the recovery of actinides from various matrices such as cellulose and polymer [12]-[17].

In the present study, we have examined for the first time the use of dialkylalkyl phosphonates as complexing agents in supercritical medium for extraction of uranium and thorium nitrates. A series of dialkylalkyl phoshonates were synthesized in our laboratory and employed for the SFE studies. The role of co-solvents in the extraction of uranium and thorium nitrates in $\mathrm{Sc}-\mathrm{CO}_{2}$ medium was investigated. The extraction behaviour of phosphonates has been compared with trialkylphosphates, trialkyl phosphine oxides and octyl phenyl N,N-diisobutylcarbomylmethyl phosphine oxide (CMPO) and the results are discussed.

\section{Experimental}

\subsection{SFE System}

SFE system used in this study comprises of a carbon dioxide pump, a modifier co-solvent pump, a constant temperature oven $\left( \pm 1^{\circ} \mathrm{C}\right)$ and an automatic back pressure regulator. Extraction vessels of $1 \mathrm{~mL} / 10 \mathrm{~mL}$ capacity were employed for carrying out the experiments. The carbon dioxide used was $>99 \%$ pure.

\subsection{Reagents}

The phosphonates were synthesised by Michaelis-Becker reaction [18]. The precursor for dialkylalkyl phosphonate based extractants is dialkylhydrogen phosphonate and was prepared by treating $\mathrm{PCl}_{3}$ with corresponding alcohols; the same involves reaction of sodium with dialkylhydrogen phosphonate in n-hexane medium. The sodium salt of dialkylhydrogen phosphonate was subsequently treated with corresponding bromoalkane to yield dialkylalkyl phosphonates. For e.g. dibutylbutyl phosphonate (DBBP) was synthesized by reacting dibutylhydrogen phosphonate with sodium to yield sodium salt of dibutylhydrogen phosphonate; the sodium salt was subsequently treated with butyl bromide to obtain DBBP. A similar procedure was adopted for the synthesis of other linear and branched phosphonates. The products were vacuum distilled and characterized by CHNS, IR and NMR techniques. The ligands, tri-sec-butyl phosphate (TsBP) and octylphenyl N,N-diisobutylcarbomylmethylphosphine oxide (CMPO) were prepared in our laboratory and used for the SFE studies. The ligands tributyl phosphate (TBP, 99\%, Alfa) and trioctylphosphine oxide (TOPO 99\% Merck) were used as such without purification.

\subsection{SFE of Uranium and Thorium Nitrates}

Sc- $\mathrm{CO}_{2}$ modified with various organophosphorus compounds such as TBP, TsBP, phosphonates, TOPO and CMPO was used for extraction of metal nitrates of uranium and thorium. The phosphonates employed for the extraction were, dibutylbutyl phosphonate (DBBP), diamylamyl phosphonate (DAAP), dibutylhexyl phosphonate (DBHeP), diamylhexyl phosphonate (DAHeP), di-iso-amylbutyl phosphonate (DiABP), di-iso-amylamyl phosphonate (DiAAP), and di-iso-amylhexyl phosphonate (DiAHeP). These ligands were dissolved in an appropriate 
co-solvent and mixed with Sc- $\mathrm{CO}_{2}$ for the extraction of uranium and thorium nitrates. The solid metal nitrates were loaded on to a $1 \mathrm{~mL}$ extraction vessel, typically $0.2 \mathrm{mmol}$ each and the extraction was carried out at a typical pressure of 300 bar and at a temperature of $45^{\circ} \mathrm{C}$ with a Sc- $\mathrm{CO}_{2}$ flow rate of $2.5 \mathrm{~mL} / \mathrm{min}$; co-solvent flow rate employed was $0.1 \mathrm{~mL} / \mathrm{min}$. The extracts were collected in a small volume of chloroform at regular intervals and the uranium and thorium were back stripped into the aqueous phase with $0.01 \mathrm{~N} \mathrm{HNO}_{3}$. The un-extracted remains of salts after SFE were washed, collected in $0.01 \mathrm{~N} \mathrm{HNO}_{3}$ and analyzed for the uranium and thorium contents.

\subsection{SFE of Uranyl Nitrate Using CMPO}

SFE of uranyl nitrate was carried out with CMPO in various co-solvents having a wide range of dielectric constants. Uranyl nitrate crystals (typically $100 \mathrm{mg}$ ) were loaded on to a $1 \mathrm{~mL}$ extraction vessel and Sc-CO $\mathrm{C}_{2}$ was allowed to pass through the vessel at a pressure of 300 bar and at $45^{\circ} \mathrm{C}$; about $3 \mathrm{wt} \% \mathrm{CMPO}$ dissolved in a cosolvent was employed along with $\mathrm{Sc}-\mathrm{CO}_{2}$. The extract was collected in isopropanol medium and was subsequently evaporated under a heat lamp and the dried sample containing uranium was recovered by sonication with dilute $\mathrm{HNO}_{3}(0.01 \mathrm{~N})$ for its assay.

In some studies, the uranium-CMPO complex was prepared and its extraction behaviour was compared with in-situ SFE complexation method. Appropriate amounts of uranyl nitrate (1 mmol) were dissolved in $1 \mathrm{~N} \mathrm{HNO}_{3}$ medium and mixed with a solution of CMPO (2 mmol) dissolved in n-hexane. The solution mixture was shaken for about 30 minutes and the organic phase containing the complex $\mathrm{UO}_{2}\left(\mathrm{NO}_{3}\right)_{2}-2 \mathrm{CMPO}$ was used for the SFE studies. The complex was subjected to various SFE studies.

Assay of $\mathbf{U}$ and Th extracts: The assay of uranium/thorium was carried out using reversed phase HPLC technique with $\mathrm{C}_{18}$ column as the stationary phase and $\alpha$-hydroxyisobutyric acid ( $\alpha$-HIBA, $0.1 \mathrm{M}, \mathrm{pH}$ : 3.2$)$ as the mobile phase [19]. The eluate from the HPLC column was mixed with post-column reagent, Arsenazo (III) and the metal complex was monitored at $655 \mathrm{~nm}$. The remains (un-extract) of the uranyl/thorium nitrate in the extraction vessel were washed, collected in $0.01 \mathrm{~N} \mathrm{HNO}_{3}$ and analyzed for uranium content.

\section{Results and Discussions}

\subsection{SFE of Uranium Thorium Nitrates Using Phosphonates}

The metal nitrates, uranium/thorium when subjected to SFE using Sc- $\mathrm{CO}_{2}$ modified with a co-solvent methanol resulted in their complete extraction ( 99\%). The addition of a polar co-solvent to $\mathrm{Sc}-\mathrm{CO}_{2}$ phase increases the polarity of the $\mathrm{Sc}-\mathrm{CO}_{2}$ medium, which helps in solubilising the metal nitrates into this medium. Under these conditions, the metal nitrates were extracted together.

The extractants, dibutylbutyl phosphonate (DBBP) as well as diamylamyl phosphonate (DAAP) were dissolved in methanol (co-solvent) and employed along with $\mathrm{Sc}-\mathrm{CO}_{2}$ for the extraction of uranium and thorium nitrates. Use of these ligands in methanol as a co-solvent with $\mathrm{Sc}-\mathrm{CO}_{2}$ resulted in the complete extraction of uranium and thorium nitrates in less than 30 minutes; however both $U$ and Th were extracted together without fractionation. Introduction of n-hexane as a co-solvent containing these phosphonates into Sc-CO $\mathrm{C}_{2}$ stream has modified the extraction behaviour; the extraction became slow and also resulted in some fractionation between uranium and thorium. In case of DBBP, the extraction efficiency was found to be about 52\% and 31\% for uranium and thorium respectively whereas with DAAP, it was $86 \%$ and $78 \%$ for $U$ and Th respectively. Total extraction period employed was $\sim 7$ hours (Figure 1). The longer chain DAAP is better extractant (with 15 carbons) for uranium and thorium than DBBP (12 carbons) when employed in the supercritical $\mathrm{CO}_{2}$ medium. The DAAP is less polar than DBBP and hence it may be possible that the corresponding metal complex can get solubilized and extracted better in non-polar carbon dioxide medium.

The SFE behaviour of metal nitrates in $\mathrm{Sc}-\mathrm{CO}_{2}$ medium containing DBHeP and DAHeP in n-hexane as a cosolvent is shown in Figure 2. DAHeP with higher carbon content exhibits better extraction efficiency compared to DBHeP.

The extraction of metal nitrates with di-isoamylalkyl phosphonates is shown in Figure 3. An increase in the alkyl chain length favours the extraction of both $U$ and Th and this could be due to the formation of more hydrophobic complexes with higher phosphonates, which are relatively more soluble in Sc- $\mathrm{CO}_{2}$ medium. Further studies are required to understand the relative solubilities of these metal species in $\mathrm{Sc}-\mathrm{CO}_{2}$ medium. The extraction efficiencies on SFE of metal nitrates with various phosphonates are summarized in Table 1. 


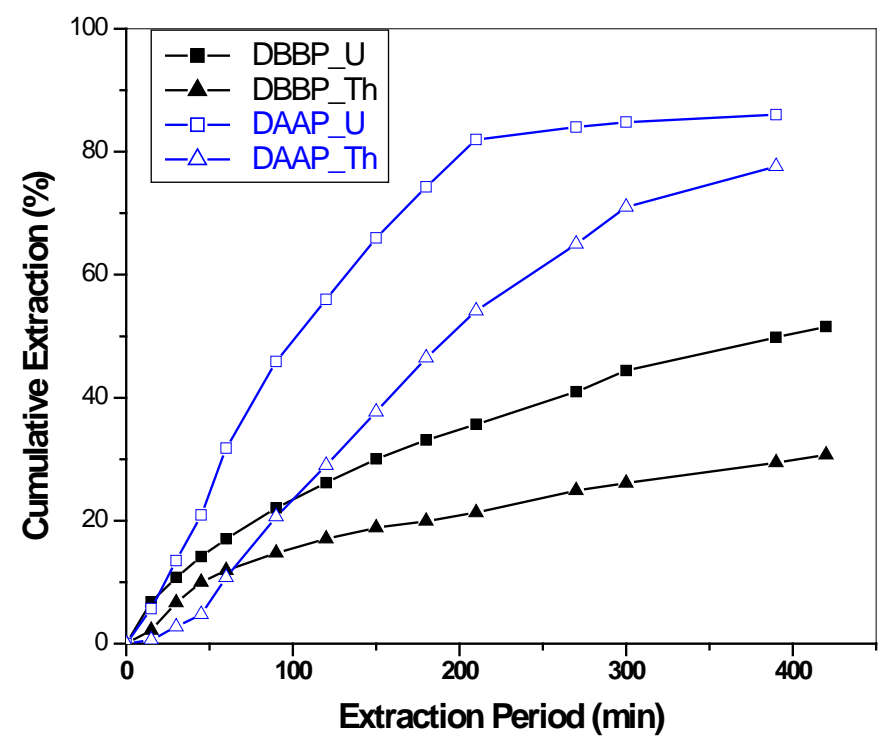

Figure 1. SFE of uranium and thorium nitrates using $\mathrm{Sc}-\mathrm{CO}_{2}$ modified with DBBP/DAAP in n-hexane medium (3 wt\% DBBP/DAAP in n-hexane). Expl.: P: 300 bar; Temp.: $45^{\circ} \mathrm{C}$; $\mathrm{Sc}-\mathrm{CO}_{2}$ flow rate: 2.5 $\mathrm{mL} / \mathrm{min}$; co-solvent flow rate: $0.1 \mathrm{~mL} / \mathrm{min}$.

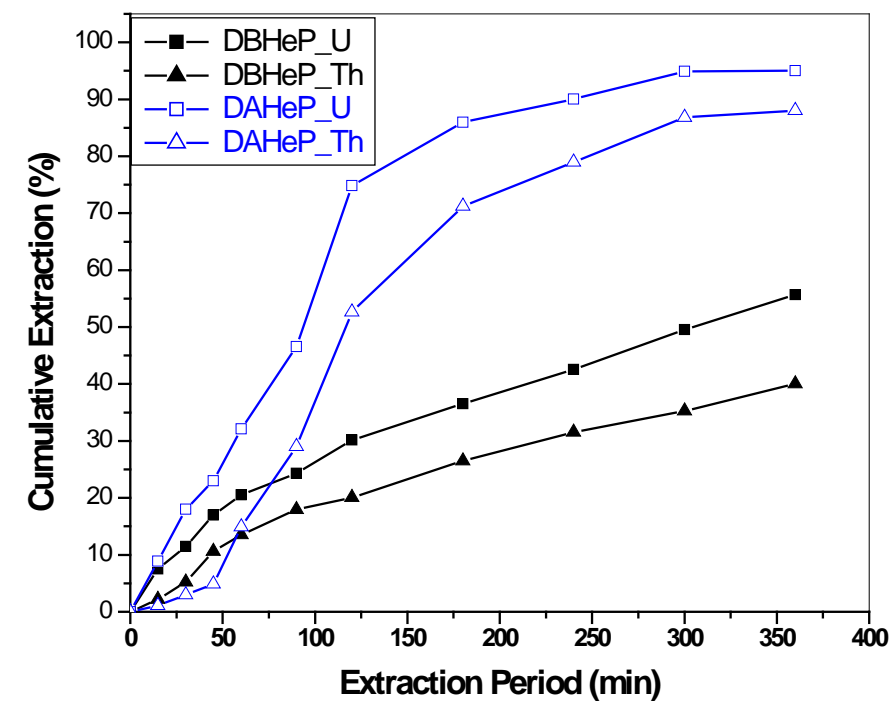

Figure 2. SFE of uranium and thorium nitrates using $\mathrm{Sc}-\mathrm{CO}_{2}$ modified with DBHeP \& DAHeP in n-hexane (3 wt\% DBHeP/DAHeP in n-hexane). Expl.: P: 300 bar; Temp.: $45^{\circ} \mathrm{C}$; $\mathrm{Sc}-\mathrm{CO}_{2}$ flow rate: 2.5 $\mathrm{mL} / \mathrm{min}$; co-solvent flow rate: $0.1 \mathrm{~mL} / \mathrm{min}$.

\subsection{SFE with Trialkyl Phosphates}

SFE of metal nitrates was carried out initially using $\mathrm{Sc}-\mathrm{CO}_{2}$ modified with TBP/TsBP using methanol as a co-solvent. Complete extraction of uranium and thorium nitrates was observed in less than 30 minutes. In fact in the first 15 min period, about $90 \%$ of both uranium and thorium nitrates were extracted (Figure 4). Uranyl nitrate forms complex with TBP $\left[\left(\mathrm{UO}_{2}\left(\mathrm{NO}_{3}\right)_{2} \cdot 2 \mathrm{TBP}\right)\right]$ and TsBP $\left[\left(\mathrm{UO}_{2}\left(\mathrm{NO}_{3}\right)_{2} \cdot 2 \mathrm{TsBP}\right)\right]$, which acts as Lewis base and the resultant adduct extraction is facilitated by methanol into the carbon dioxide medium. Similarly, thorium forms $\mathrm{Th}\left(\mathrm{NO}_{3}\right)_{4} \cdot 3 \mathrm{TBP} /\left(\mathrm{Th}\left(\mathrm{NO}_{3}\right)_{4} \cdot 3 \mathrm{TsBP}\right.$, which are soluble in the $\mathrm{Sc}-\mathrm{CO}_{2}$ stream. Both uranium and thorium species were extracted together under these experimental conditions. 


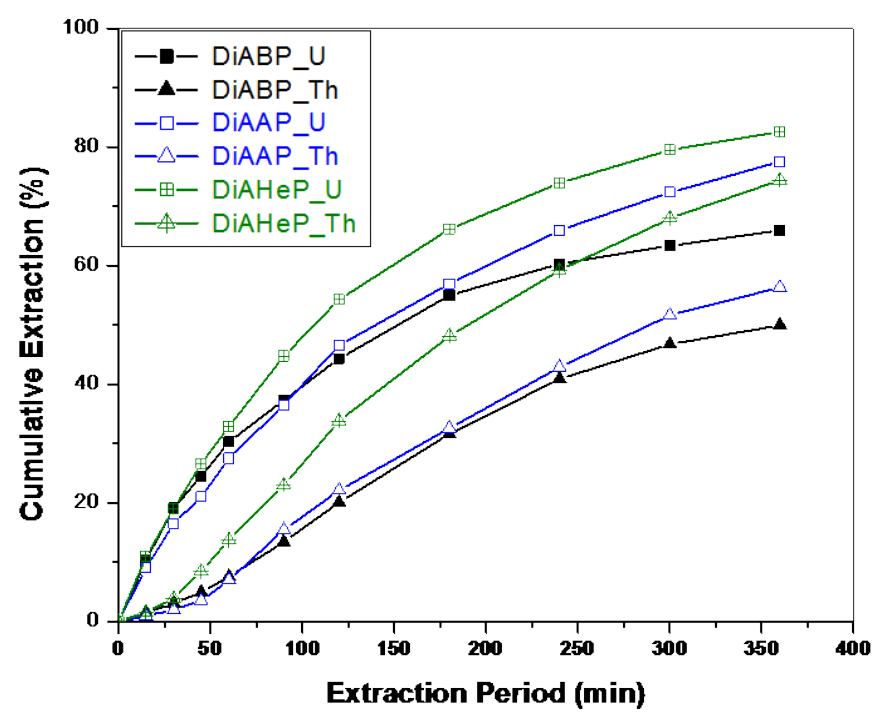

Figure 3. SFE of uranium and thorium nitrates using $\mathrm{Sc}-\mathrm{CO}_{2}$ modified with di-isoamylalkyl phsophonates in n-hexane (3 wt\% diisoamylalkyl phsophonates in n-hexane). Expl.: P: 300 bar; Temp.: $45^{\circ} \mathrm{C} ; \mathrm{Sc}-\mathrm{CO}_{2}$ flow rate: $2.5 \mathrm{~mL} / \mathrm{min}$; co-solvent flow rate: 0.1 $\mathrm{mL} / \mathrm{min}$.

Table 1. Extraction efficiency of $U$ and Th nitrates with various phosphonates. Expl.: P: 300 bar; Temp.: $45^{\circ} \mathrm{C}$; $\mathrm{Sc}-\mathrm{CO}_{2}$ flow rate: $2.5 \mathrm{~mL} / \mathrm{min}$; co-solvent flow rate: $0.1 \mathrm{~mL} / \mathrm{min}$. $3 \mathrm{wt} \%$ phosphonates in n-hexane used as co-solvent. Extraction period: 6 hrs.

\begin{tabular}{cccc}
\hline S.No & Phosphonate & \multicolumn{2}{c}{ Extraction efficiency (\%) } \\
\cline { 3 - 4 } & & U & Th \\
\hline 1. & DAAP & 86 & 75 \\
2 & DBBP & 48 & 28 \\
3 & DAHeP & 95 & 88 \\
4 & DBHeP & 56 & 40 \\
5. & DiABP & 66 & 50 \\
6. & DiAAP & 75 & 60 \\
7. & DiAHeP & 80 & 74 \\
\hline
\end{tabular}

Sc- $\mathrm{CO}_{2}$ modified with TBP in n-hexane/dichloromethane as co-solvent medium was subsequently investigated to study the role of co-solvent on the extraction behaviour; extraction kinetics became sluggish in the presence of these co-solvents. When co-solvents, dichloromethane as well as n-hexane were employed, about 80\% of the extraction was obtained only after 6 hours. However, in these experiments, some preferential extraction of uranium over thorium was observed in the initial period of the extraction and with increasing extraction period, uranium and thorium were extracted together. Thus the polar co-solvent, methanol provides faster extraction without fractionation whereas the non-polar solvents, n-hexane/dichloromethane provided marginal fractionation of metal nitrates though the extraction kinetics was slower. These results indicated that co-solvents play an important role in the extraction/fractionation of metal nitrates.

Similarly, the extraction of uranium and thorium nitrates was examined using $\mathrm{Sc}-\mathrm{CO}_{2}$ containing TsBP in n-hexane medium. About 50\% - 60\% of $U$ and Th were extracted when a co-solvent of $3 \mathrm{wt} \% \mathrm{TsBP}$ in n-hexane was used (Figure 5). The influence of TsBP concentration in $\mathrm{Sc}-\mathrm{CO}_{2}$ medium was also studied for studying the fractionation behaviour; however, the extraction rate was very slow when TsBP concentration in the co-solvent medium was kept at 0.1 to $0.5 \mathrm{wt} \%$ in n-hexane.

The extraction behaviour of metal nitrates was also examined without a co-solvent in some experiments [15]. In these experiments, solid uranyl nitrate and thorium nitrate mixtures were taken in a $1 \mathrm{~mL}$ extraction vessel 


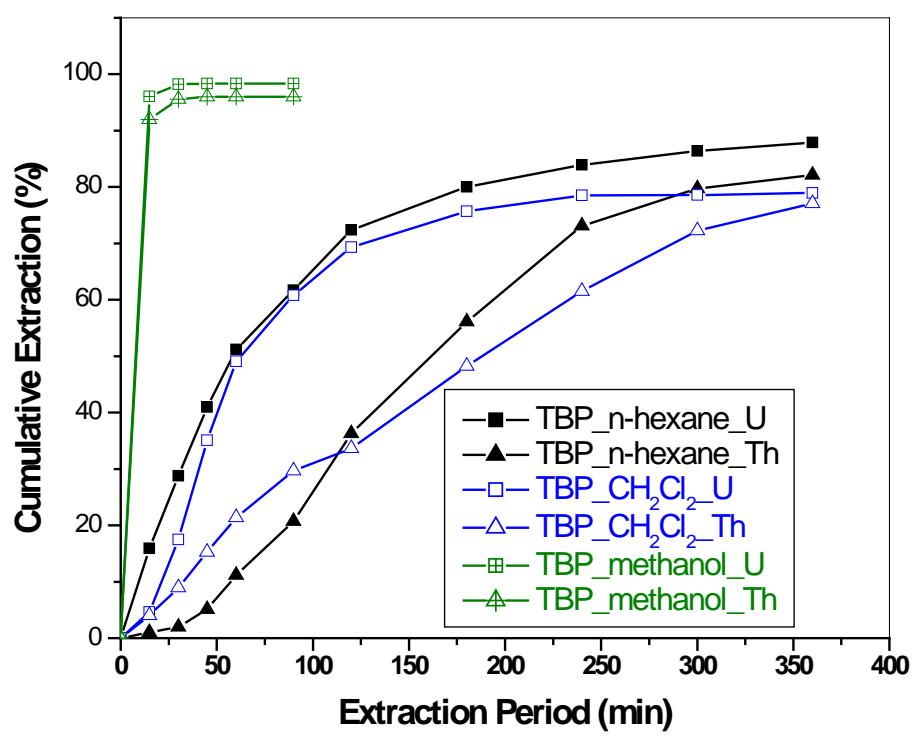

Figure 4. SFE of uranium and thorium nitrates using Sc- $\mathrm{CO}_{2}$ modified with TBP in various co-solvents (3 wt\% TBP in co-solvents). Expl.: P: 300 bar; Temp.: $45^{\circ} \mathrm{C}$; $\mathrm{Sc}-\mathrm{CO}_{2}$ flow rate: $2.5 \mathrm{~mL} / \mathrm{min}$; co-solvent flow rate: $0.1 \mathrm{~mL} / \mathrm{min}$.

and connected in a downstream of $10 \mathrm{~mL}$ ligand delivery vessel containing the ligand, TBP or TsBP. In these experiments, $\mathrm{Sc}-\mathrm{CO}_{2}$ was allowed to pass through the ligand delivery vessel first and the resultant modified $\mathrm{CO}_{2}$ stream was passed through the extraction vessel containing uranium and thorium nitrates. The extraction efficiency after $5 \mathrm{hr}$ period with TBP was 73\% - 79\% for uranium and 71\% - 72\% for thorium; with TsBP, the extraction efficiency after $21 / 2 \mathrm{hr}$ period was $55 \%$ - 58\% and 50\% - 55\% for uranium and thorium respectively. No significant fractionation of uranium over thorium was observed even in these experiments.

The distribution coefficients of uranium and thorium with TBP and TsBP were earlier measured under solvent extraction conditions from our laboratory [20]. The D value of uranium (tracer) for $1.1 \mathrm{M}$ solutions of TBP and TsBP from $3 \mathrm{M}$ nitric acid at $303 \mathrm{~K}$ is 24.5 and 37.6 respectively. The D values for thorium under identical conditions with TBP and TsBP are 2.9 and 0.45 . The separation factors for uranium and thorium with TBP and TsBP are 8.4 and 83.5 respectively. TBP offers lower separation factor than TsBP-because of the branching of substituents in TsBP cause trisolvated thorium to be less stable and hence aids in the preferential extraction of uranium over thorium. Figure 5 shows the extraction efficiency observed during SFE of U and Th with TsBP; the relative extraction efficiency is almost identical though there was some fractionation. Even when acid solvates of TBP/TsBP were used with Sc- $\mathrm{CO}_{2}$, the relative extraction of uranium and thorium was not significantly different. Thus the mechanism operating under the SFE conditions may not be similar to the solvent extraction conditions and further studies are required to understand the mechanism of extraction and the relatively poor fractionation of uranium over thorium

\subsection{SFE of Uranium Thorium Nitrates Using Tri-n-octyl Phosphine Oxide (TOPO) in n-Hexane}

Sc- $\mathrm{CO}_{2}$ modified with TOPO in the presence of n-hexane as a co-solvent was employed for the extraction of uranium and thorium nitrates. Use of TOPO resulted in the co-extraction of thorium with uranium, right from the initial phase of extraction. The extraction ability of the organophosphorus extractant depends on the basicity of the phosphoryl oxygen atom and the nature of the substituents attached to the phosphorous atom. The basicity on the phosphoryl oxygen in the neutral organophosphorus extractant series is found to increase in the order, phosphates $<$ phosphonates $<$ phosphinates $<$ phosphine oxides. Use of stronger extractant like TOPO resulted in the co-extraction of uranium and thorium with no selectivity irrespective of the polarity of the co-solvent employed. Even with a strong complexing ligand like TOPO, the extraction of metal nitrate was very slow when n-hexane was added as a co-solvent to the $\mathrm{Sc}-\mathrm{CO}_{2}$ stream (Figure 6). 


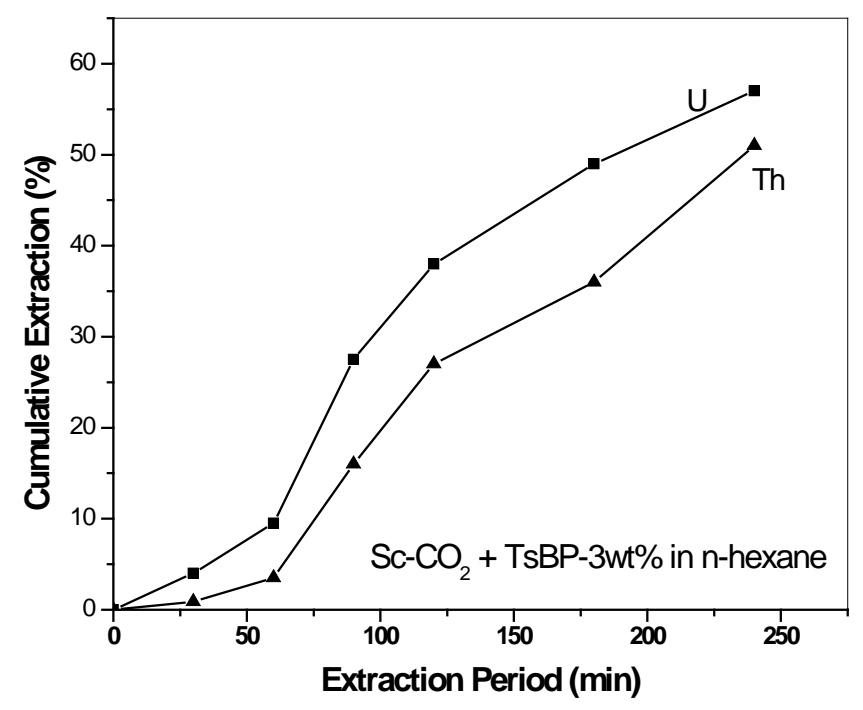

(a)

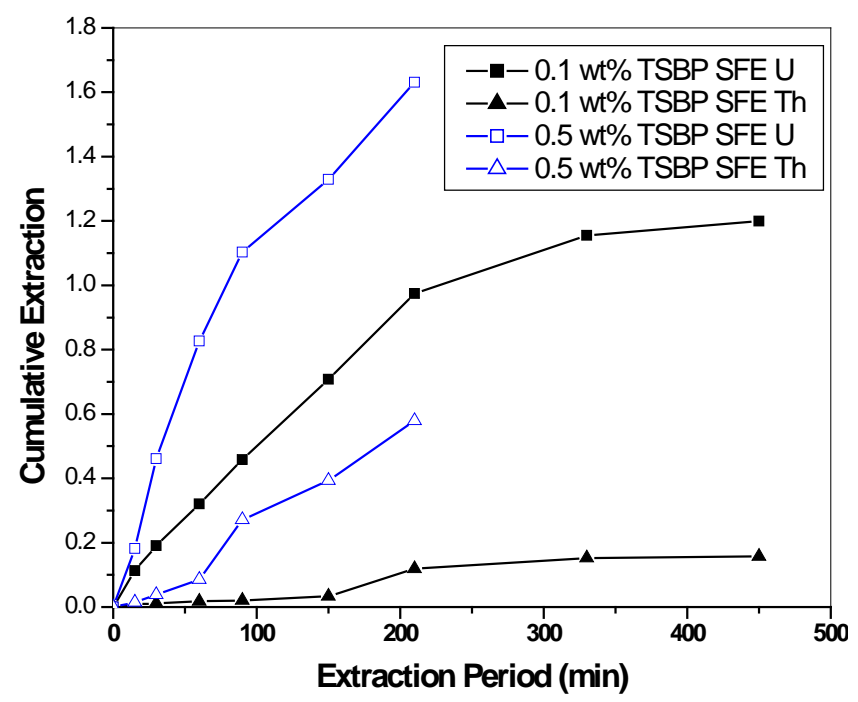

(b)

Figure 5. (a) SFE of uranium and thorium nitrates using Sc- $\mathrm{CO}_{2}$ modified TsBP (3 wt\%) using n-hexane as a co-solvent. Expl.: P: 300 bar; Temp.: $45^{\circ} \mathrm{C}$; $\mathrm{Sc}-\mathrm{CO}_{2}$ flow rate: $2.5 \mathrm{~mL} / \mathrm{min}$; co-solvent flow rate: $0.1 \mathrm{~mL} / \mathrm{min}$; (b) SFE of uranium and thorium nitrates using Sc- $\mathrm{CO}_{2}$ containing TsBP in n-hexane medium. Expl.: P: 300 bar; Temp.: $45^{\circ} \mathrm{C}$; $\mathrm{Sc}-\mathrm{CO}_{2}$ flow rate: $2.5 \mathrm{~mL} / \mathrm{min}$; co-solvent flow rate: $0.1 \mathrm{~mL} / \mathrm{min}$.

\subsection{SFE of Uranyl Nitrate with CMPO in the Presence of Various Co-Solvents}

To study the role of dielectric constant of the co-solvent in the extraction process, SFE of neat uranium nitrate was carried out with CMPO in various co-solvents. The dielectric constant of the co-solvents used was ranging from 2 - 33. Use of polar co-solvents such as methanol and isopropanol in $\mathrm{Sc}-\mathrm{CO}_{2}$ medium resulted in the complete extraction of uranyl nitrate; the extraction efficiency was drastically reduced when non-polar co-solvents e.g. hexane were employed. The presence of polar nitrate moieties and six water molecules in the uranyl nitrate hexahydrate demands polar medium (e.g. methanol, isopropanol) for solubilising the metal nitrates into the Sc- $\mathrm{CO}_{2}$ medium containing CMPO. The formation of metal solvate depends on the dielectric constant of the medium (Table 2). The polarity of the solvent increases with the dielectric constant of the medium, leading to 


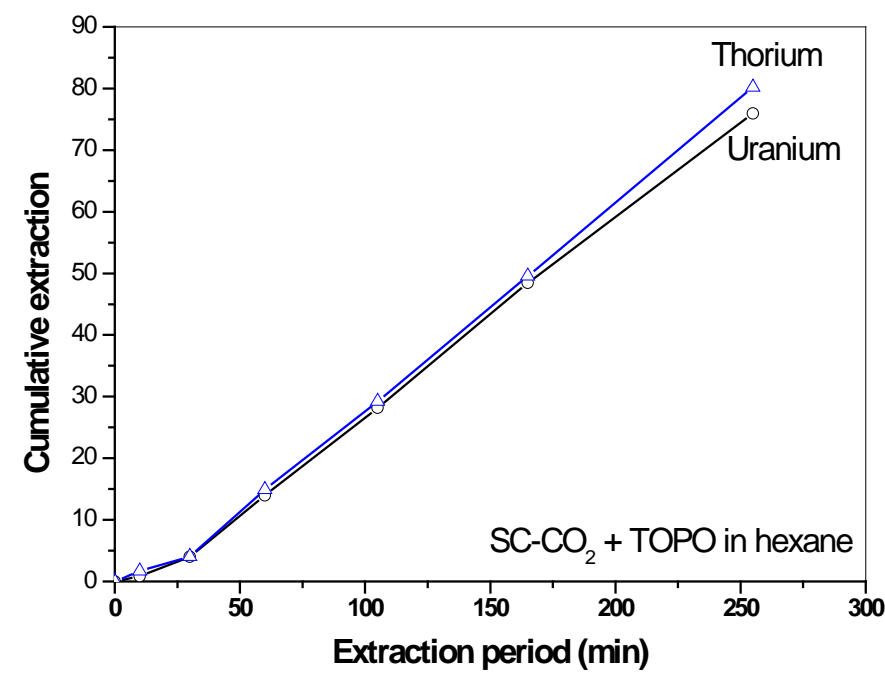

Figure 6. SFE of uranium and thorium nitrates using Sc- $\mathrm{CO}_{2}$ modified with TOPO in n-hexane (3 wt\% TOPO in n-hexane). Expl.: P: 300 bar; Temp.: $45^{\circ} \mathrm{C}$; $\mathrm{Sc}-\mathrm{CO}_{2}$ flow rate: $2.5 \mathrm{~mL} / \mathrm{min}$; co-solvent flow rate: $0.1 \mathrm{~mL} / \mathrm{min}$.

Table 2. Influence of co-solvent on the extraction of uranium using CMPO. Expl.: P: 300 bar; Temp.: $45^{\circ} \mathrm{C}$; $\mathrm{Sc}-\mathrm{CO}_{2}$ flow rate: $2.5 \mathrm{~mL} / \mathrm{min}$; co-solvent flow rate: $0.1 \mathrm{~mL} / \mathrm{min}$. Sample: uranyl nitrate; $3 \mathrm{wt} \%$ of $\mathrm{CMPO}$ in a co-solvent used along with $\mathrm{Sc}-\mathrm{CO}_{2}$.

\begin{tabular}{cccc}
\hline S.No & $\begin{array}{c}\text { Medium: } \mathrm{Sc}-\mathrm{CO}_{2}+\mathrm{CMPO} \\
\text { dissolved in a co-solvent } \\
\text { Co-solvent }\end{array}$ & $\begin{array}{c}\text { Dielectric constant } \\
\text { of co-solvent }\end{array}$ & Uranium extraction (\%) \\
\hline 1 & $\begin{array}{c}\mathrm{CH}_{3} \mathrm{OH} \\
\left(\mathrm{CH}_{3}\right)_{2} \mathrm{CHCH}_{2} \mathrm{OH}\end{array}$ & 32.7 & $>99$ \\
2 & $\mathrm{CH}_{3} \mathrm{OH}+\mathrm{CH}_{2} \mathrm{Cl}_{2}$ & 18.0 & $>99$ \\
3 & $\left(\mathrm{CH}_{3}\right)_{2} \mathrm{CHOH}_{2}$ & 20.8 & $>99$ \\
4 & $\mathrm{CH}_{2} \mathrm{Cl}_{2}$ & 17.5 & $>99$ \\
5 & $\mathrm{CHCl}_{3}$ & 8.93 & 7 \\
6 & $\mathrm{C}_{6} \mathrm{H}_{14}$ & 4.81 & 5 \\
7 & & 2.02 & $<1$ \\
\hline
\end{tabular}

charge stabilization and solvation in $\mathrm{CO}_{2}$ medium. Use of Sc- $\mathrm{CO}_{2}$ containing $\mathrm{CMPO}$ in the presence of co-solvent e.g. hexane has resulted in poor extraction of metal nitrate $(<1 \%)$ and extraction of uranium was better with increase in dielectric constant of the medium. Thus extraction efficiency of uranium increases when dielectric constant of the medium was raised from 2 to 18.

Experiments were also performed by preparing the $\mathrm{UO}_{2}\left(\mathrm{NO}_{3}\right)_{2} \cdot 2 \mathrm{CMPO}$ complex followed by its SFE with Sc- $\mathrm{CO}_{2}$ in order to understand in-situ SFE complexation against SFE with pre-prepared metal complex. The CMPO metal complex was spiked on a cellulose matrix and subjected to SFE using neat $\mathrm{Sc}-\mathrm{CO}_{2}$ as well as Sc- $\mathrm{CO}_{2}$ modified with n-hexane/methanol as co-solvents. The results are shown in Table 3. About $80 \%-90 \%$ extraction was observed with neat Sc- $\mathrm{CO}_{2}$ as well as $\mathrm{Sc}-\mathrm{CO}_{2}$ with n-hexane as the co-solvent whereas complete extraction was observed in the presence of Sc- $\mathrm{CO}_{2}$ with methanol as a co-solvent. These studies have established that once the complex (metal solvate) is formed, presence of hexane in the supercritical medium did not prevent extraction of uranium-CMPO solvate unlike the earlier case where in-situ complexation (CMPO in hexane mixed with $\mathrm{Sc}-\mathrm{CO}_{2}$ followed by passing the stream through uranyl nitrate) is essential for the extraction of uranyl nitrate.

Introduction of ligand with n-hexane as a co-solvent into the Sc- $\mathrm{CO}_{2}$ medium generally slows down the extraction of metal nitrates. Marginal fractionation of metal nitrates was observed with phosphonates and phosphates when introduced into $\mathrm{Sc}-\mathrm{CO}_{2}$ stream using co-solvents which have lower dielectric constant. Use of bulkier ligands e.g. CMPO with n-hexane as the co-solvent in $\mathrm{Sc}_{-} \mathrm{CO}_{2}$ medium has severely reduced the extraction 
Table 3. Extraction efficiency of uranium-CMPO complex in $\mathrm{Sc}-\mathrm{CO}_{2}$ medium (Uranyl nitrate - CMPO complex prepared externally and loaded on to a cellulose matrix followed by SFE).

\begin{tabular}{ccc}
\hline S.No. & SFE conditions & Uranium extraction (\%) \\
\hline 1 & neat $\mathrm{Sc}-\mathrm{CO}_{2}$ & $77-82^{*}$ \\
2 & $\mathrm{Sc}-\mathrm{CO}_{2}+$ hexane & $80-92^{*}$ \\
3 & $\mathrm{Sc}^{*} \mathrm{CO}_{2}+\mathrm{MeOH}$ & $>98^{\#}$ \\
\hline
\end{tabular}

Expl.: P: 300 bar; Temp.: $45^{\circ} \mathrm{C}$; $\mathrm{Sc}-\mathrm{CO}_{2}$ flow rate: $2.5 \mathrm{~mL} / \mathrm{min}$; co-solvent flow rate: $0.1 \mathrm{~mL} / \mathrm{min}$. ${ }^{*}$ Results of 6 independent experiments; " results of three independent experiments.

of metal nitrates. Further studies on the relative solubilities of metal complexes in $\mathrm{Sc}-\mathrm{CO}_{2}$ medium in the presence of co-solvents will pave way for development of better separation procedures.

\section{Conclusion}

Sc- $\mathrm{CO}_{2}$ modified with various organophosphorous compounds was investigated for the extraction of uranium and thorium nitrates. Complete extraction of metal nitrates of both uranium and thorium was observed when the organophosphorous ligand was introduced using a polar co-solvent, e.g. methanol into the Sc- $\mathrm{CO}_{2}$ medium. Addition of methanol into Sc- $\mathrm{CO}_{2}$ phase helps in improving the solubility of the metal complex in carbon dioxide medium through solvation; the complexes of uranium and thorium with organophosphorous compounds are more soluble in $\mathrm{Sc}-\mathrm{CO}_{2}$ medium in the presence of solvents with high dielectric constant $(>20)$ than that with solvents of low dielectric constant $(2$ - 10), e.g. n-hexane. Thus the extraction efficiency as well as fractionation is dependent on the nature of co-solvent employed with the $\mathrm{Sc}-\mathrm{CO}_{2}$ phase. These studies have established that co-solvent plays a major role in extraction and fractionation of the metal ions and our studies have demonstrated that n-hexane as co-solvent was better in general compared to methanol for fractionation of metal ions using modified Sc- $-\mathrm{CO}_{2}$.

\section{References}

[1] Caude, M. and Thiebaut, D. (1999) Practical Supercritical Fluid Chromatography and Extraction. Harwood Academic Publishers, Chur.

[2] Erkey, C. (2000) Supercritical Carbon Dioxide Extraction of Metals from Aqueous Solutions: A Review. Journal of Supercritical Fluids, 17, 259-287. http://dx.doi.org/10.1016/S0896-8446(99)00047-9

[3] Laintz, K.E., Wai, C.M., Yonker, C.R. and Smith, R.D. (1992) Extraction of Metal Ions from Liquid and Solid Materials by Supercritical Carbon Dioxide. Analytical Chemistry, 64, 2875-2878. http://dx.doi.org/10.1021/ac00046a039

[4] Wai, C.M. (1995) Supercritical Fluid Extraction of Trace Metals from Solid and Liquid Materials for Analytical Applications. Analytical Sciences, 11, 165-167. http://dx.doi.org/10.2116/analsci.11.165

[5] Lin, Y., Brauer, R.D., Laintz, K.E. and Wai, C.M. (1993) Supercritical Fluid Extraction of Lanthanides and Actinides from Solid Materials with a Fluorinated $\beta$-Diketone. Analytical Chemistry, 65, 2549-2551. http://dx.doi.org/10.1021/ac00066a027

[6] Iso, S., Uno, S., Meguro, Y., Sasaki, T. and Yoshida, Z. (2000) Pressure Dependence of Extraction Behaviour of Plutonium (IV) and Uranium (VI) from Nitric Acid Solution to Supercritical Carbon Dioxide Containing Tributyl Phosphate. Progress in Nuclear Energy, 37, 423-428. http://dx.doi.org/10.1016/S0149-1970(00)00082-2

[7] Tomioka, O., Meguro, Y., Enokida, Y., Yamamoto, I. and Yoshida, Z. (2001) Dissolution Behaviour of Uranium Oxides with Supercritical CO2 Using HNO3-TBP Complex as a Reactant. Journal of Nuclear Science and Technology, 38, 1097-1102. http://dx.doi.org/10.1080/18811248.2001.9715141

[8] Mincher, B.J., Fox, R.V., Holmes, R.G.G., Robbins, R.A. and Boardman, C. (2001) Supercritical Fluid Extraction of Plutonium and Americium from Soil Using Theonytrifluoroacetone and Tributylphosphate Complexation. Radiochimica Acta, 89, 613-617.

[9] Lin, Y., Wai, C.M., Jean, F.M. and Brauer, R.D. (1994) Supercritical Fluid Extraction of Thorium and Uranium Ions from Solid and Liquid Materials with Fluorinated beta Diketones and Tributyl Phosphate. Environmental Science and Technology, 28, 1190-1193. http://dx.doi.org/10.1021/es00055a034

[10] Rao, A., Kumar, P. and Ramakumar, K.L. (2010) Separation of Uranium from Different Uranium Oxide Matrices Employing Supercritical Carbon Dioxide Extraction. Journal of Radioanalytical and Nuclear Chemistry, 285, 247-257. http://dx.doi.org/10.1007/s10967-010-0568-7 
[11] Smart, N.G., Carleson, T., Kast, T., Clifford, A.A., Burford, M.D. and Wai, C.M. (1997) Solubility of Chelating Agents and Metal Containing Compounds in Supercritical Fluid Carbon Dioxide. Talanta, 44, 137-150. http://dx.doi.org/10.1016/S0039-9140(96)02008-5

[12] Kumar, R., Sivaraman, N., Senthil Vadivu, E., Srinivasan, T.G. and Vasudeva Rao, P.R. (2003) Complete Removal of Uranyl Nitrate from Tissue Matrix Using Supercritical Fluid Extraction. Radiochimica Acta, 91, 197-201. http://dx.doi.org/10.1524/ract.91.4.197.19966

[13] Kumar, R., Sivaraman, N., Sujatha, K., Srinivasan, T.G. and Vasudeva Rao, P.R. (2007) Removal of Plutonium and Americium from Waste Matrices by Supercritical Carbon Dioxide Extraction. Radiochimica Acta, 95, 577-584. http://dx.doi.org/10.1524/ract.2007.95.10.577

[14] Suresh Kumar, V., Kumar, R., Sivaraman, N., Ravisankar, G. and Vasudeva Rao, P.R. (2010) Design and Adaptation of a Novel Supercritical Extraction Facility for Operation in a Glove Box for Recovery of Radioactive Elements. Review of Scientific Instruments, 81, 094101-094106. http://dx.doi.org/10.1063/1.3484190

[15] Kumar, R., Sivaraman, N., Sujatha, K., Srinivasan, T.G. and Vasudeva Rao, P.R. (2009) A Novel Technique for Modifier Free Delivery of Ligands for Supercritical Fluid Extraction. Radiochimica Acta, 97, 443-451. http://dx.doi.org/10.1524/ract.2009.1633

[16] Sujatha, K., Pitchaiah, K.C., Sivaraman, N., Srinivasan, T.G. and Vasudeva Rao, P.R. (2012) Recovery of Uranium and Plutonium from Waste Matrices Using Supercritical Fluid Extraction. American Journal of Analytical Chemistry, 3, 916-922. http://dx.doi.org/10.4236/ajac.2012.312A121

[17] Sujatha, K., Pitchaiah, K.C., Sivaraman, N., Nagarajan, K., Srinivasan, T.G. and Vasudeva Rao, P.R. (2014) Recovery of Plutonium from Polymeric Waste Matrices Using Supercritical Fluid Extraction. Desalination and Water Treatment, 52, 470-475. http://dx.doi.org/10.1080/19443994.2013.808729

[18] Brahmmananda Rao, C.V.S., Srinivasan, T.G. and Vasudeva Rao, P.R. (2012) Studies on the Extraction by Substituted Butyl Phosphonates. Solvent Extraction and Ion Exchange, 30, 262-277. http://dx.doi.org/10.1080/07366299.2011.639250

[19] Datta, A., Sivaraman, N., Srinivasan, T.G. and Vasudeva Rao, P.R. (2011) Liquid Chromatographic Behaviour of Actinides and Lanthanides on Monolith Supports. Radiochimica Acta, 99, 275-283. http://dx.doi.org/10.1524/ract.2011.1816

[20] Suresh, A., Srinivasan, T.G. and Vasudeva Rao, P.R. (1994) Extraction of U(VI), Pu(IV) and Th(IV) by Some Trialkyl Phosphates. Solvent Extraction and Ion Exchange, 12, 727-744. http://dx.doi.org/10.1080/07366299408918234 
Scientific Research Publishing (SCIRP) is one of the largest Open Access journal publishers. It is currently publishing more than 200 open access, online, peer-reviewed journals covering a wide range of academic disciplines. SCIRP serves the worldwide academic communities and contributes to the progress and application of science with its publication.

Other selected journals from SCIRP are listed as below. Submit your manuscript to us via either submit@scirp.org or Online Submission Portal.
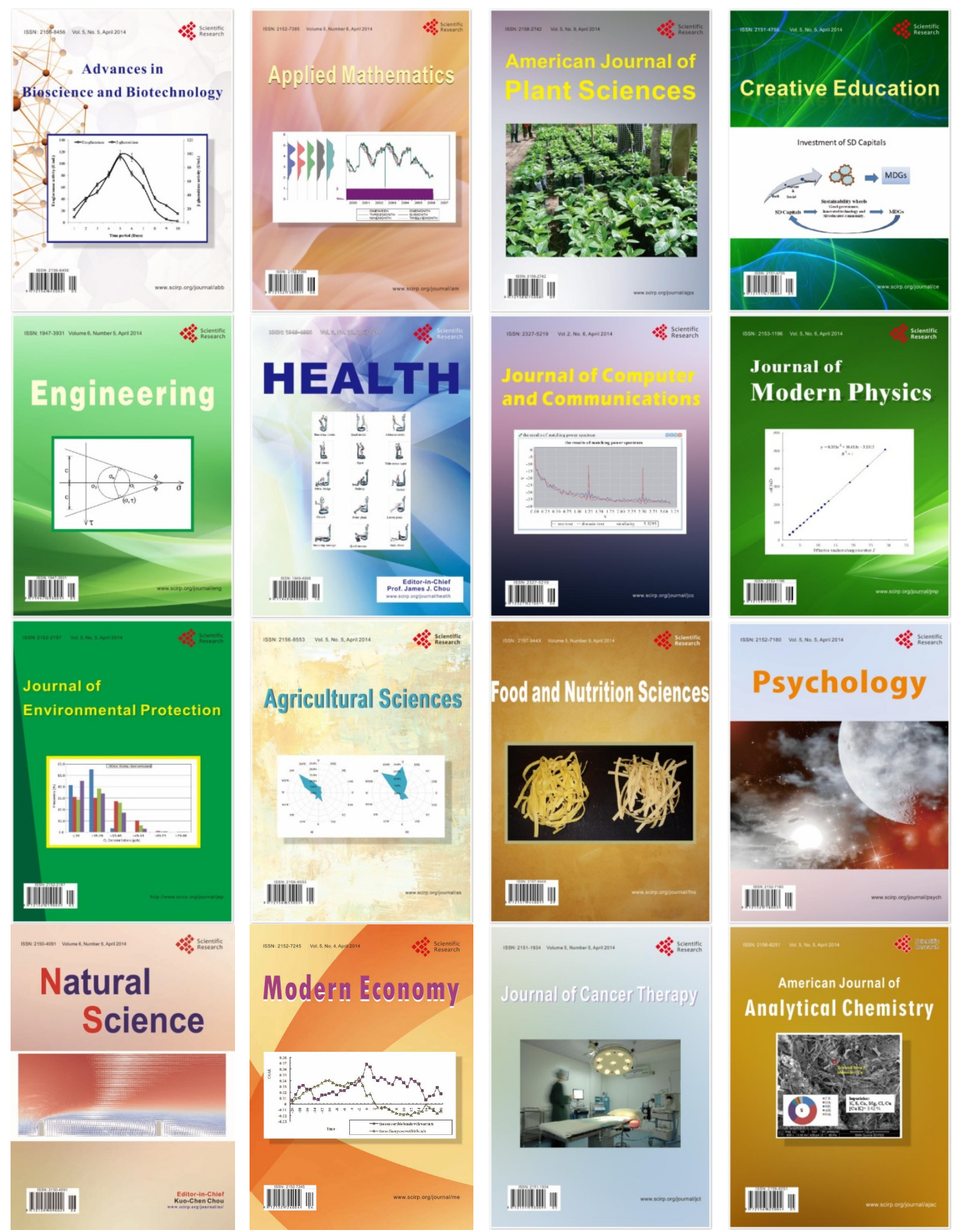